\title{
AMAR
}

Andalas Management Review (AMAR)

Vol. 4, No. 2 (2020) 16

The Management Institute, Faculty of Economics, Universitas Andalas

ISSN (Print) 2476-9282 | ISSN (Online) 2548-155X

\section{Pengaruh Celebrity Endorser, Online Advertising dan Word of Mouth terhadap Minat Beli Konsumen pada E-Commerce Tokopedia}

\author{
M. Arief Algiffarya, Zakaria Wahabb, Muchsin Saggaff Shihabc, Marlina Widiyantid \\ aProgram Studi Magister Manajemen Universitas Sriwijaya, ariefalgiffary@gmail.com \\ bProgram Studi Magister Manajemen Universitas Sriwijaya, zkwahab01@gmail.com \\ cProgram Studi Magister Manajemen Universitas Sriwijaya, muchsin.shihab@bakrie.ac.id \\ dProgram Studi Magister Manajemen Universitas Sriwijaya, marlinawidiyanti68@yahoo.co.id
}

\begin{abstract}
Abstrak
Penelitian ini bertujuan untuk mengetahui pengaruh celebrity endorser, online advertising dan word of mouth terhadap minat beli konsumen pada e-commerce Tokopedia. Populasi dalam penelitian ini adalah masyarakat Indonesia pengguna media sosial Instagram berusia 15-34 tahun yang merupakan pengguna pasif atau belum menggunakan e-commerce Tokopedia pada tahun 2020. Sampel dalam penelitian ini sebanyak 100 responden dengan menggunakan teknik purposive random sampling. Metode pengumpulan data menggunakan kuesioner yang disebar melalui google form dan teknik pengolahan data menggunakan analisis regresi linier berganda. Hasil dari analisis menunjukkan bahwa celebrity endorser berpengaruh positif dan signifikan terhadap minat beli konsumen pada e-commerce Tokopedia. Online advertising berpengaruh positif dan signifikan terhadap minat beli konsumen pada e-commerce Tokopedia. Word of mouth berpengaruh positif dan signifikan terhadap minat beli konsumen pada e-commerce Tokopedia. Hasil penelitian ini dapat digunakan sebagai masukan bagi Tokopedia dalam upaya untuk dapat meningkatkan minat beli konsumen.
\end{abstract}

Keyword: Celebrity Endorser, Online Advertising, Word of Mouth, Minat Beli

\section{PENDAHULUAN}

Di era globalisasi seperti sekarang ini pesatnya perkembangan teknologi terutama internet, telah mengubah pola hidup dan perilaku manusia, salah satunya dalam hal berbelanja. Kemudahan kemampuan dalam mengakses internet membuat masyarakat mengubah kegiatan berbelanjanya dari yang semula berbelanja di toko konvensional, beralih menjadi berbelanja di toko online atau biasa disebut $e$-commerce, tak terkecuali di Indonesia.

Berdasarkan hasil studi Polling Indonesia berkerja sama dengan Asosiasi Penyelenggara Jasa Internet Indonesia (APJII), pada 2018 jumlah pengguna internet di Indonesia tumbuh sebesar 10,12\%. Menurut Ketua Umum APJII Henri Kasyfi Soemartono (kompas.com, 2019), pengguna internet di Indonesia mencapai 171,17 juta pengguna. Angka tersebut meningkat dibanding tahun sebelumnya yang berjumlah 143,26 juta pengguna. Berdasarkan proyeksi Badan Pusat Statistik (BPS) di tahun yang sama, penduduk Indonesia 
berjumlah sekitar 264,16 juta jiwa. Dari data-data tersebut, dapat disimpulkan bahwa lebih dari setengah dari jumlah penduduk atau lebih tepatnya 64,8 persen penduduk di Indonesia telah mengetahui dan menggunakan internet.

Meningkatnya jumlah pengguna internet di Indonesia juga berbanding lurus dengan meningkatnya konsumen yang berbelanja online di Indonesia. Berdasarkan survey yang dilakukan oleh wearesocial.com pada semester I tahun 2019 sebanyak 60,5\% responden diketahui lebih memilih untuk melakukan kegiatan berbelanja secara online daripada mengunjungi offline store. Terdapat peningkatan persentase pada masyarakat yang melakukan transaksi e-commerce sebesar 5.9\% dibandingkan tahun sebelumnya dan hal ini juga masih dapat meningkat dikarenakan penetrasi pasar e-commerce di Indonesia masih cukup rendah, yakni sebesar 40\% (binus.ac.id, 2020).

Tokopedia merupakan salah satu e-commerce terbesar di Indonesia yang mengusung model bisnis marketplace C2C (customer to customer), suatu model bisnis yang bergantung kepada pihak ke-3 sebagai penerima dan penyalur uang. Tokopedia yang didirikan pada 17 Agustus 2009, memungkinkan individu, toko kecil, dan merek untuk membuka dan mengelola toko online.

Pada kuartal III di tahun 2019 lalu, iPrice Group menobatkan Tokopedia sebagai $e$ commerce dengan jumlah pengunjung web bulanan terbesar. Total pengunjung web bulanan Tokopedia mencapai 66 juta pengunjung. Selanjutnya diisi oleh Shopee sebanyak 56 juta pengunjung dan Bukalapak dengan 42,9 juta pengunjung (katadata.co.id, 2020).

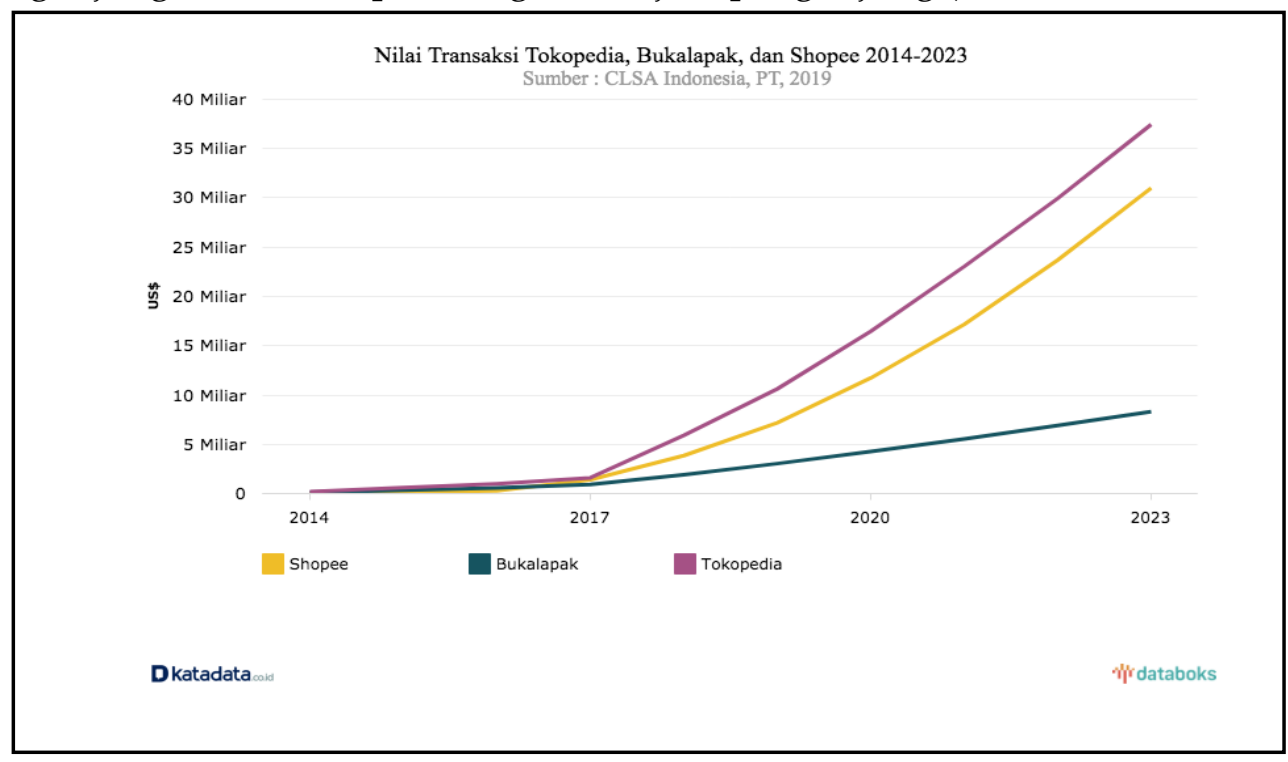

Gambar 1. Nilai Transaksi Tokopedia, Bukalapak dan Shopee 2014-2023

Sumber: katadata.co.id, 2020 
Dari segi nilai transaksi, laporan CLSA menunjukkan Tokopedia sebagai $e$ commerce dengan nilai transaksi terbesar di Indonesia. Tokopedia memimpin nilai transaksi tertinggi sejak 2014 dan diprediksi masih terus bertahan hingga 2023. Tercatat pada 2018, nilai transaksi Tokopedia sebesar US\$ 5,9 miliar. CLSA juga memproyeksikan pada 2023 nilai transaksi tokopedia mencapai US\$ 37,45 miliar. Sementara nilai transaksi Shopee dan Bukalapak, diproyeksikan masing-masing sebesar US\$ 31 miliar dan US\$ 8,3 miliar pada 2023. Secara umum, total nilai transaksi tiga besar e-commerce pada 2019 sebesar US $\$ 11,6$ miliar dan meningkat pada 2023 hingga mencapai US\$ 76,8 miliar (katadata.co.id, 2020).

Fenomena ini menunjukkan terjadinya peningkatan minat beli konsumen dalam berbelanja online. Menurut (Kotler \& Amstrong, 2012), minat beli adalah suatu perasaan yang muncul setelah menerima rangsangan dari produk yang dilihatnya, lalu muncul keinginan untuk membeli dan memilikinya. Dengan demikian, minat beli adalah suatu perasaan tertarik terhadap suatu barang atau jasa yang menjadi awal dari keputusan pembelian pada konsumen.

Minat beli pada konsumen tercipta karena adanya beberapa faktor, salah satunya adalah promosi. Menurut (Kotler, 2000), promosi merupakan bagian dan proses strategi pemasaran sebagai cara untuk berkomunikasi dengan pasar dengan menggunakan komposisi bauran promosi. Kegiatan promosi dilakukan oleh suatu perusahaan, menurut (Swastha, 2000), bertujuan untuk memberikan informasi terhadap produk yang dijual, membujuk dan mempengaruhi konsumen untuk membeli produk yang dijual, menciptakan kesan atau image terhadap produk yang dijual, dan merupakan suatu alat untuk mencapai tujuan dari perusahaan .

Pentingnya promosi dalam berbisnis disadari oleh banyak pelaku bisnis dalam meningkatkan penjualan, tak terkecuali e-commerce. Data riset yang dikeluarkan oleh Adstensity menunjukkan bahwa para pelaku e-commerce di Indonesia mengeluarkan banyak dana di bidang promosi, terutama periklanan (indotelko.com, 2019). Perusahaan e-Commerce Shopee berada pada urutan pertama sebagai $e$-commerce dengan total pengeluaran sebesar Rp 825,62 miliar sepanjang kuartal III 2019. Disusul berikutnya Blibli sebesar Rp 500 miliar, Traveloka sebesar Rp 472,37 miliar, serta Misteraladin sebesar Rp 429,63 miliar. Sedangkan Tokopedia berada di urutan ke-5 dengan dana yang dihabiskan sebesar Rp 336,08 miliar. Dari data tersebut dapat diketahui bahwa promosi sangatlah penting bagi para pelaku bisnis apapun dalam melakukan kegiatan bisnisnya. 
Penelitian ini dilakukan dengan tujuan untuk mengetahui dan menganalisis pengaruh dari strategi-strategi dalam kegiatan promosi seperti celebrity endorser, online advertising, dan word of mouth terhadap minat beli konsumen pada e-commerce Tokopedia.

\subsection{Minat Beli}

Menurut (Kotler \& Amstrong, 2012) minat beli adalah suatu pola pikir yang muncul setelah menerima rangsangan dari produk yang dilihat, lalu muncul keinginan untuk membeli dan memiliki. Menurut (Schiffman \& Kanuk, 2009) minat beli adalah suatu kekuatan psikologis di dalam individu, yang berujung pada suatu tindakan. Minat beli dianggap sebagai tolak ukur terhadap kemungkinan konsumen membeli produk, dimana tingginya minat beli berdampak pada kemungkinan yang cukup besar terjadinya keputusan pembelian.

(Ferdinand, 2014) menyatakan minat beli diidentifikasi melalui indikator-indikator berikut:

a. Minat Transaksional

Minat Transaksional merupakan suatu keinginan seseorang untuk membeli suatu produk.

b. Minat Referensial

Minat Referensial merupakan suatu keinginan seseorang untuk mereferensikan suatu produk kepada orang lain.

c. Minat Preferensial

Minat Preferensial merupakan suatu keinginan yang menggambarkan perilaku seseorang yang memiliki preferensi utama pada suatu produk. Preferensi ini hanya dapat digantikan jika terjadi sesuatu dengan produk preferensinya.

d. Minat Eksploratif

Minat Eksploratif merupakan suatu keinginan yang diperlihatkan pada perilaku seseorang yang terus mencari informasi untuk mendukung sifat-sifat positif dari suatu produk.

\subsection{Celebrity Endorser}

Menurut (Shimp, 2014), endorser (bintang iklan) merupakan bintang televisi, aktor/aktris film, atlet, ataupun orang terkenal lainnya yang dapat menimbulkan kepercayaan orang lain terhadap apa yang disampaikan. Jadi, perusahaan atau produsen mengenalkan suatu mereknya melalui iklan dan didukung dengan menggunakan bintang iklan (endorser) supaya bisa meningkatkan efektivitas iklan dan menarik konsumen agar tertarik membeli produk tersebut. Celebrity endorsement adalah strategi menggunakan artis sebagai bintang iklan di media-media mulai dari media cetak, media sosial, maupun media televisi.

Menurut (Shimp, 2014), dimensi celebrity endorser dibagi menjadi 3, yaitu: 
a. Kepercayaan (Trustworthy)

Memiliki definisi sebagai dapat dipercaya dan diandalkan, Kepercayaan meliputi kejujuran, integritas dan dapat dipercaya masyarakat atau konsumen sebagai sumber informasi yang valid.

b. Keahlian (Expertise)

Memiliki keterampilan khusus, pengetahuan atau kemampuan sehubungan dengan merek yang didukung.

c. Daya Tarik (Attractiveness)

Bukan hanya mengacu pada sisi daya tarik secara fisik, tetapi juga dari sikap dan tindakan yang terlihat dari para celebrity, gaya hidup, dan sebagainya.

\subsection{Online Advertising}

Iklan (advertising) adalah segala bentuk penyajian dan promosi ide, barang atau jasa secara nonpersonal oleh suatu sponsor tertentu yang memerlukan pembayaran (Kotler \& Armstrong, 2012). Iklan internet (online advertising) merupakan salah satu periklanan yang banyak digunakan perusahaan-perusahaan dalam mempromosikan produk yang dihasilkannya di era globalisasi ini (Sumarwan, 2010).

(Aqsa, 2018) menyatakan dimensi dalam iklan online terbagi menjadi dua faktor, yaitu:

\section{a. Communicate}

Dimensi tentang bagaimana sebuah iklan online menampilkan suatu informasi dan komunikasi tentang produk tersebut sehingga pengguna memperoleh informasi tentang produk yang ada di iklan tersebut, terdiri dari interactivity dan accessibility.

b. Content

Dimensi tentang bagaimana bentuk, tata letak dan grafis yang ditampilkan oleh iklan online sehingga menarik minat pengguna untuk melihat iklan online, terdiri dari: entertaining, informativeness, irritation, credibility.

\subsection{Word of Mouth}

Menurut (Kotler \& Keller, 2016), WoM Communication atau komunikasi dari mulut ke mulut merupakan proses komunikasi yang berbentuk pemberian rekomendasi baik secara individu maupun kelompok terhadap suatu produk yang bertujuan untuk memberikan informasi secara personal.

Dalam penelitian (Sweeney, Soutar, dan Mazzarol, 2012) terdapat 3 dimensi WoM yang didasari oleh pemberi (sender) dan penerima (receiver) pesan, yaitu :

a. Cognitive content 
Dimensi yang menggambarkan isi pesan sesuai dengan kinerja, respon terhadap masalah, dan persepsi, harga-nilai, sehingga mendukung gagasan bahwa WoM juga memiliki dimensi rasional.

b. Richness of content

Dimensi yang merupakan suatu kedalaman, intensitas, dan kejelasan dari pesan itu sendiri. Kekayaan meliputi aspek konten, seperti bahasa digunakan dan informasi yang terlibat dalam pesan.

c. Strength of delivery

Dimensi yang yaitu kekuatan dari jalan pesan disampaikan. Ini berkaitan dengan cara dimana pesan tersebut disampaikan bukan dengan konten. Hal ini mencerminkan kekuatan niat rekomendasi.

\subsection{Penelitian Terdahulu}

Penelitian-penelitian terdahulu yang meneliti tentang celebrity endorser yang memberikan pengaruh terhadap minat beli konsumen diantaranya dilakukan oleh (Utarsih, 2019) bahwa variabel celebrity endorser memiliki pengaruh signifikan terhadap minat beli konsumen. Hasil penelitian dari (Utarsih, 2019) didukung pula oleh hasil penelitian dari (Tanjung \& Hudrasyah, 2019); (Khan, 2018); (Vien, Yun, \& Fai, 2018); (Savitri, 2017); (Bues, Steiner, Stafflage, \& Krafft, 2017); (Mubarok, 2016); (Astuti \& Santoso, 2016); (Andaru \& Pradekso, 2016); (Pratiwi \& Moeliono, 2015); (Totoatmojo, 2015).

Online advertising dapat menumbuhkan minat beli konsumen. Penelitian yang dilakukan oleh (Arnianti, Khoirunnisa, Arzaqi, Geulis, \& Herlina, 2019); (Islamy \& Yoestini, 2019); (Savitri, 2017); (Astuti \& Santoso, 2016); (Andaru \& Pradekso, 2016); (Jurnia \& Rosyad, 2015); (Arief \& Millanyani, 2015) dan (Aqsa \& Kartini, 2015) menunjukkan bahwa online advertising berpegaruh positif dan signifikan terhadap minat beli konsumen.

Pada pengaruh word of mouth terhadap minat beli konsumen, ditemukan juga perbedaan antara peneliti satu dengan peneliti lainnya, seperti pada penelitian yang dilakukan oleh (Widjaja, 2016), yang mendapatkan hasil bahwa terdapat pengaruh yang signifikan dari word of mouth terhadap minat beli konsumen. Didukung pula oleh penelitian yang dilakukan oleh (Prabowo, 2016); (Lim, 2015); (Kalele, Oroh, \& Sumarauw, 2015); (Nurvidiana, 2015); (Aprilia, 2015); (Lin \& Lu, 2010) dan (Chang \& Chin, 2010) yang mendapatkan hasil yang sama dengan penelitian sebelumnya.

\subsection{Kerangka Pikir dan Hipotesis}

Kerangka pemikiran disajikan dalam gambar sebagai berikut: 


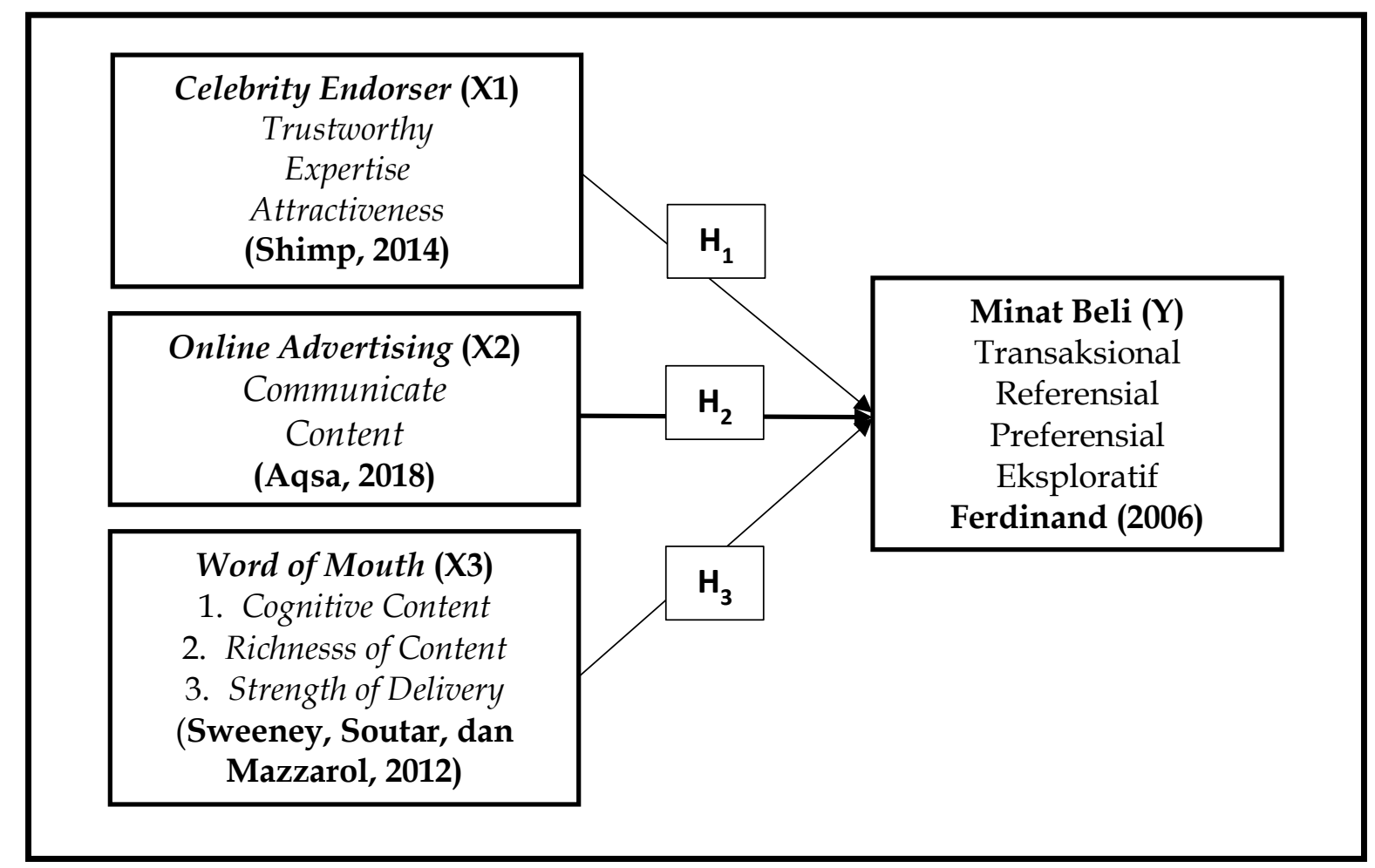

Gambar 2. Kerangka Pemikiran

Sumber: Diolah dari Kuesioner, 2020

Berdasarkan kajian teori dan kerangka berfikir maka dapat disusun hipotesis sebagai berikut:

$\mathrm{H}_{1}$ : Celebrity Endorser berpengaruh signifikan terhadap minat beli konsumen pada e-commerce Tokopedia.

$\mathrm{H}_{2}$ : Online Advertising berpengaruh signifikan terhadap minat beli konsumen pada e-commerce Tokopedia.

$\mathrm{H}_{3}$ : Word of Mouth berpengaruh signifikan terhadap minat beli konsumen pada e-commerce

Tokopedia. 


\section{METODE}

\subsection{Jenis Penelitian}

Penelitian ini bersifat penelitian kausal. Hal ini dikarenakan penelitian ini bertujuan untuk meneliti hubungan sebab-akibat antara variabel bebas Celebrity Endorser, Online Advertising, dan Word of Mouth, dan variabel terikat Minat Beli.

\subsection{Teknik Pengumpulan Data}

Data yang digunakan dalam penelitian ini diperoleh dari kuesioner skala likert yang terdiri dari 5 skala yang disebar secara online melalui akun media sosial Instagram peneliti. Kuesioner akan disebar secara online melalui fitur "direct message" pada media sosial Instagram peneliti, dimana calon responden yang mendapatkan kuesioner tersebut adalah orang-orang yang berada pada daftar "following" media sosial Instagram peneliti sehingga peneliti dapat mengetahui calon responden yang berminat untuk mengisi kuesioner dan menjadi responden penelitian melalui jawaban calon responden ketika dihubungi oleh peneliti.

\subsection{Populasi dan Sampel}

Populasi dalam penelitian ini adalah masyarakat Indonesia pengguna media sosial Instagram berusia 15-34 tahun yang merupakan pengguna pasif atau belum menggunakan $e$ commerce Tokopedia pada tahun 2020. Sampel yang akan digunakan dalam penelitian ini adalah 100 orang masyarakat Indonesia pengguna media sosial Instagram berusia 15-34 tahun yang merupakan pengguna pasif atau belum menggunakan e-commerce Tokopedia pada tahun 2020. Pengambilan sampel dalam penelitian ini akan menggunakan teknik non probability sampling bersifat purposive random sampling.

\subsection{Teknik Analisis Data}

Metode yang digunakan dalam penelitian ini adalah analisis regresi linier berganda. Metode ini berguna untuk mengetahui pengaruh hubungan secara langsung antara dua variabel atau lebih variabel bebas dengan satu variabel terikat maka digunakan teknik analisis regresi linier berganda. Dalam penelitian ini adalah antara variabel bebas celebrity endorser $\left(\mathrm{X}_{1}\right)$, online advertising $\left(\mathrm{X}_{2}\right)$, word of mouth $\left(\mathrm{X}_{3}\right)$ dan variabel terikat minat beli $(\mathrm{Y})$.

\section{HASIL DAN PEMBAHASAN}

\subsection{Hasil Analisis Regresi Linier Berganda}

Analisis regresi linier berganda dilakukan untuk mengetahui pengaruh variabel celebrity endorser (X1), online advertising (X2), dan word of mouth (X3) terhadap minat beli konsumen $(Y)$. Berdasarkan hasil pengujian diperoleh sebagai berikut: 
Tabel 1

Hasil Analisis Regresi Linier Berganda

\begin{tabular}{llcccc}
\hline \multicolumn{5}{c}{ Coefficients } \\
Model & \multicolumn{4}{c}{$\begin{array}{l}\text { Unstandardized } \\
\text { Coefficients }\end{array}$} & $\begin{array}{c}\text { Standardized } \\
\text { Coefficients }\end{array}$ \\
\hline \multirow{2}{*}{$\mathbf{1}$} & & $\mathrm{B}$ & $\begin{array}{c}\text { Std. } \\
\text { Error }\end{array}$ & Beta & Sig \\
\hline \multirow{4}{*}{ Constant } & 5.011 & 1.802 & & .007 \\
& Celebrity Endorser & .170 & .077 & .162 & .029 \\
& Online Advertising & .276 & .098 & .252 & .006 \\
& Word of Mouth & .419 & .079 & .480 & .000 \\
\hline
\end{tabular}

Sumber: Diolah dari Kuesioner, 2020

Berdasarkan pada Tabel 1, hasil analisis regresi linier berganda dapat dinyatakan dengan persamaan sebagai berikut:

$$
\mathrm{Y}=5,011+0,170 \mathrm{X}_{1}+0,276 \mathrm{X}_{2}+0,419 \mathrm{X}_{3}+\mathrm{e}
$$

Persamaan regresi linier di atas dapat dijelaskan sebagai berikut:

a. Nilai konstanta menunjukkan nilai positif dengan nilai sebesar 5,011. Hal ini menunjukkan bahwa minat beli konsumen pada Tokopedia dianggap bahwa dengan tanpa adanya pengaruh celebrity endorser, online advertising dan word of mouth, maka besarnya variabel minat beli sebesar 5,011.

b. Nilai koefisien regresi variabel celebrity endorser sebesar 0,170 dengan nilai

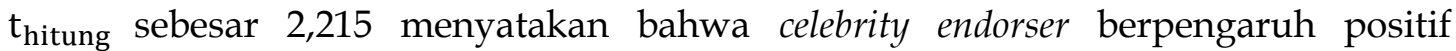
terhadap minat beli. Hal ini menunjukkan bahwa semakin tinggi celebrity endorser, maka akan berdampak positif yaitu semakin tinggi minat beli konsumen pada $e$ commerce Tokopedia.

c. Nilai koefisien regresi variabel online advertising sebesar 0,276 dengan nilai

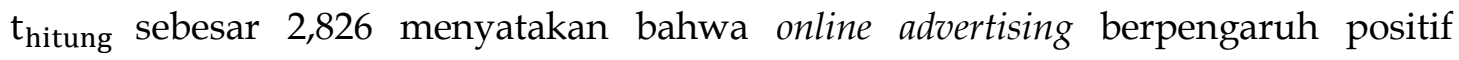
terhadap minat beli. Hal ini menunjukkan bahwa semakin tinggi online advertising, maka akan berdampak positif yaitu semakin tinggi minat beli konsumen pada $e$ commerce Tokopedia.

d. Nilai koefisien regresi variabel word of mouth sebesar 0,419 dengan nilai $t_{\text {hitung }}$ sebesar 5,314 menyatakan bahwa word of mouth berpengaruh positif terhadap minat beli. Hal ini menunjukkan bahwa semakin tinggi word of mouth, maka akan berdampak positif yaitu semakin tinggi minat beli konsumen pada e-commerce Tokopedia.

\subsection{Hasil Uji Koefisien Korelasi (r) dan Koefisien Determinasi $\left(\mathbf{R}^{2}\right)$}

Tabel 2 
Hasil Uji Koefisien Korelasi (r) dan Koefisien Determinasi $\left(\mathbf{R}^{2}\right)$

Model Summaryb

\begin{tabular}{ccccc}
\hline Model & R & R Square & $\begin{array}{c}\text { Adjusted R } \\
\text { Square }\end{array}$ & $\begin{array}{c}\text { Std. Error of the } \\
\text { Estimate }\end{array}$ \\
\hline 1 & .734 & .539 & .525 & 1.359 \\
\hline Sumber: Diolah dari Kuesioner & 2020 & & &
\end{tabular}

Berdasarkan output model summary pada Tabel 2, hasil uji koefisien korelasi (r) terlihat bahwa besarnya pengaruh variabel celebrity endorser, online advertising dan word of mouth yaitu sebesar 0,734 atau sebesar $73,4 \%$. Besarnya angka $R$ square $\left(R^{2}\right)$ adalah 0,539 atau sebesar $53,9 \%$, angka tersebut digunakan untuk melihat bagaimana celebrity endorser, online advertising, dan word of mouth berpengaruh terhadap minat beli konsumen pada e-commerce Tokopedia.

Angka tersebut mempunyai maksud bahwa bagaimana variabel celebrity endorser, online advertising, dan word of mouth dalam menunjukkan faktor apa saja yang dapat mempengaruhi minat beli konsumen pada e-commerce Tokopedia dan secara bersama-sama sebesar 53,9\% sedangkan sisanya 46,1\% dipengaruhi oleh faktor-faktor lain.

\subsection{Hasil Uji Signifikansi Parameter Individual (Uji t)}

Uji signifikansi parameter individual (uji t) bertujuan untuk mengetahui seberapa jauh pengaruh variabel bebas secara individual terhadap variabel terikat. Penelitian ini dengan signifikansi $5 \%$ atau $\alpha=0,05$. Hasil uji $\mathrm{t}$ dapat dilihat pada Tabel 3 sebagai berikut:

Tabel 3

Hasil Uji Signifikansi Parameter Individual (Uji t)

\begin{tabular}{clcccc}
\hline Model & \multicolumn{3}{c}{ Coefficients } & & \\
& Variabel & $\mathbf{B}$ & $\mathbf{t}_{\text {tabel }}$ & $\mathbf{t}_{\text {hitung }}$ & Sig. \\
\hline 1 & Celebrity Endorser & .170 & 1.949 & 2.215 & .029 \\
2 & Online Advertising & .276 & 1.949 & 2.826 & .006 \\
3 & Word of Mouth & .419 & 1.949 & 5.314 & .000 \\
\hline
\end{tabular}

Sumber: Diolah dari Kuesioner, 2020

Berdasarkan pada Tabel 3, nilai degree of freedom (df) $=\mathrm{n}-\mathrm{k}=100-4=96$ dan 0,05 maka diperoleh nilai $t_{\text {tabel }}$ untuk data penelitian ini adalah 1,949. Hasil analisis dapat dijelaskan sebagai berikut:

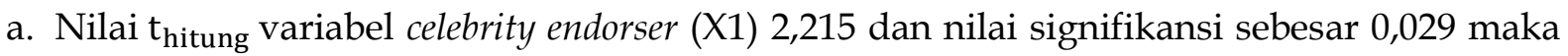
nilai $t_{\text {hitung }}>\mathrm{t}_{\text {tabel }}$ yaitu $(2,215>1,949)$ atau nilai (Sig.) $0,029<0,05$. Artinya celebrity endorser berpengaruh signifikan terhadap minat beli konsumen pada e-commerce Tokopedia. Hal ini membuktikan bahwa hipotesis pertama pada variabel celebrity endorser berpengaruh positif dan signifikan dapat diterima. 


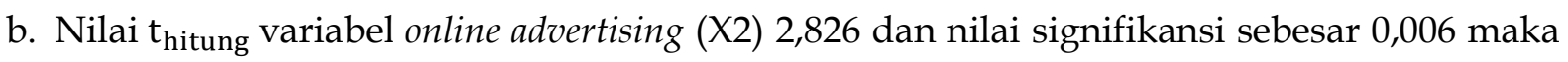
nilai $t_{\text {hitung }}>t_{\text {tabel yaitu }}(2,826>1,949)$ atau nilai (Sig.) $0,029<0,05$. Artinya online advertising berpengaruh signifikan terhadap minat beli konsumen pada e-commerce Tokopedia. Hal ini membuktikan bahwa hipotesis kedua pada variabel online advertising berpengaruh positif dan signifikan dapat diterima.

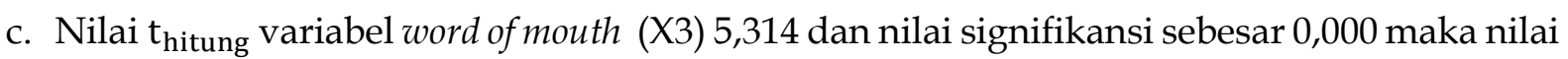
$t_{\text {hitung }}>t_{\text {tabel }}$ yaitu $(5,314>1,949)$ atau nilai (Sig.) $0,029<0,05$. Artinya word of mouth berpengaruh signifikan terhadap minat beli konsumen pada e-commerce Tokopedia. Hal ini membuktikan bahwa hipotesis ketiga pada variabel word of mouth berpengaruh positif dan signifikan dapat diterima.

\subsection{Pembahasan}

\section{a. Celebrity Endoser}

Variabel Celebrity endorser berpengaruh positif dan signifikan terhadap minat beli. Hasil penelitian ini sejalan dengan hasil penelitian dari (Utarsih, 2019); (Tanjung \& Hudrasyah, 2019); (Khan, 2018); (Vien, Yun, \& Fai, 2018); (Savitri, 2017); (Bues, Steiner, Stafflage, \& Krafft, 2017); (Mubarok, 2016); (Astuti \& Santoso, 2016); (Andaru \& Pradekso, 2016); (Pratiwi \& Moeliono, 2015); (Totoatmojo, 2015) berpengaruh positif dan signifikan terhadap minat beli konsumen. Hasil dari penelitian ini menunjukkan bahwa pada variabel celebrity endorser pada indikator celebrity endorser Tokopedia sering tampil di publik menunjukkan nilai rata-rata yang paling rendah yaitu sebesar 3,17. Hal ini menunjukkan bahwa Tokopedia lebih banyak menggunakan selebriti yang tidak sering tampil di muka umum seperti selebriti yang masih baru atau selebriti yang masih muda. Pada indikator celebrity endorser Tokopedia memiliki pengetahuan dan wawasan mengenai produk yang di endorse-nya juga mendapatkan nilai di bawah rata-rata yaitu 3,47. Hal ini diduga bahwa banyak selebriti yang diendorse oleh Tokopedia tidak menyampaikan informasi produk dengan jelas sehingga menimbulkan kesan kurangnya pengetahuan dan wawasan dari produk yang diendorse di mata konsumen. Hal yang sama juga terjadi pada indikator celebrity endorser Tokopedia memiliki kepribadian dan penampilan yang menarik dengan nilai sebesar 3,59. Hal ini diduga Tokopedia tidak terlalu menyaring selebriti yang memiliki kepribadian yang baik walau memiliki penampilan yang menarik. Pada indikator celebrity endorser Tokopedia memiliki citra yang bagus di kalangan masyarakat menunjukkan skor rata-rata tertinggi sebesar 4,40. Hal tersebut menunjukkan bahwa 
Tokopedia telah memilih selebriti yang memiliki citra bagus bagi masyarakat. Dengan citra yang bagus di kalangan masyarakat dapat memberikan daya tarik bagi konsumen dan membuat konsumen dapat berminat untuk melakukan pembelian di e-commerce Tokopedia.

b. Online advertising

Online advertising berpengaruh positif dan signifikan terhadap minat beli konsumen. Hasil penelitian ini sejalan dengan hasil penelitian dari (Arnianti, Khoirunnisa, Arzaqi, Geulis, \& Herlina, 2019); (Islamy \& Yoestini, 2019); (Savitri, 2017); (Astuti \& Santoso, 2016); (Andaru \& Pradekso, 2016); (Jurnia \& Rosyad, 2015); (Arief \& Millanyani, 2015) dan (Aqsa \& Kartini, 2015) yang menunjukkan bahwa online advertising berpengaruh positif dan signifikan terhadap minat beli konsumen. Hasil penelitian menunjukkan bahwa pada variabel online advertising pada indikator online advertising Tokopedia menarik untuk dilihat menunjukkan nilai rata-rata yang paling rendah yaitu sebesar 3,20. Hal ini menunjukkan bahwa online advertising Tokopedia memiliki desain yang kurang menarik perhatian konsumen diduga karena kebanyakan online advertising Tokopedia terlalu bersifat hard-selling. Pada indikator online advertising Tokopedia mengandung konten komunikatif dan mudah dimengerti walau sudah baik namun masih memiliki nilai sedikit di bawah rata-rata yaitu 3,79. Hal ini diduga memiliki alasan yang sama dengan indikator online advertising Tokopedia menarik untuk dilihat karena kebanyakan online advertising Tokopedia terlalu bersifat hard-selling. Sedangkan pada online advertising Tokopedia memberikan informasi yang dapat dipercaya dan kredibel juga masih di bawah rata-rata sebesar 3,77. Hal ini diduga bahwa online advertising Tokopedia tidak menyaring iklannya berdasarkan seller (penjual) yang memiliki tingkat kepercayaan dan kredibilitas tinggi di mata konsumen. Pada indikator online advertising Tokopedia memiliki informasi yang jelas mengenai suatu produk menunjukkan skor nilai rata-rata yang paling tinggi yaitu sebesar 4,69. Hal ini menunjukkan bahwa online advertising Tokopedia memiliki informasi yang jelas untuk meningkatkan minat beli konsumen. Maka, online advertising yang jelas dan menarik perhatian sangat penting dilakukan walau Tokopedia merupakan e-commerce yang sudah familiar di kalangan masyarakat.

c. Word of mouth

Word of mouth berpengaruh positif dan signifikan terhadap minat beli konsumen. Hasil penelitian ini sejalan dengan hasil penelitian dari (Widjaja, 2016); (Prabowo, 2016); (Lim, 2015); (Kalele, Oroh, \& Sumarauw, 2015); (Nurvidiana, 2015); (Aprilia, 2015); 
(Lin \& Lu, 2010) dan (Chang \& Chin, 2010) menunjukkan hasil bahwa word of mouth berpengaruh positif dan signifikan terhadap minat beli konsumen. Hasil penelitian menunjukkan bahwa pada variabel word of mouth pada indikator pesan yang diberikan melalui word of mouth dibawakan dengan menarik menunjukkan nilai skor rata-rata yang paling rendah yaitu sebesar 3,77. Hal ini diduga bahwa pemberi pesan dalam word of mouth kebanyakan adalah orang terdekat yang memberikan informasi dengan jujur dan kredibel sehingga tidak dilebihkan-lebihkan hanya agar terkesan menarik. Pada indikator pesan yang diberikan melalui word of mouth dapat dipercaya menunjukkan nilai skor rata-rata yang paling tinggi yaitu sebesar 4,85. Hal tersebut menunjukkan bahwa konsumen lebih senang mendengar promosi word of mouth dari sumber yang dipercayanya.

\section{KESIMPULAN DAN IMPLIKASI}

\subsection{Kesimpulan}

Berdasarkan hasil pembahasan di atas maka dapat diambil kesimpulan sebagai berikut:

a. Celebrity endorser berpengaruh positif dan signifikan terhadap minat beli konsumen pada e-commerce Tokopedia.

b. Online advertising berpengaruh positif dan signifikan terhadap minat beli konsumen pada e-commerce Tokopedia.

c. Word of mouth berpengaruh positif dan signifikan terhadap minat beli konsumen pada $e$ commerce Tokopedia.

\subsection{Implikasi}

Berdasarkan perumusan masalah yang telah dibahas pada bab sebelumnya maka peneliti menyarankan beberapa hal sebagai berikut:

a. Pada variabel celebrity endorser:

1) Tokopedia diharapkan dapat memilih selebriti yang lebih sering tampil di muka umum. Selebriti dengan intensitas tampil di muka umum yang tinggi dapat membuat kesan familiar pada selebriti tersebut terhadap konsumen sehingga kesan familiar menimbulkan keyakinan konsumen terhadap selebriti dan produk yang di-endorse.

2) Tokopedia diharapkan lebih banyak memberikan ilmu mengenai produk yang diendorse-kan terhadap selebriti yang digunakan untuk meningkatkan pengetahuan dan 
wawasan selebriti tersebut. Hal ini diharapkan dapat meningkatkan keyakinan konsumen terhadap informasi iklan yang disampaikan oleh selebriti tersebut.

3) Tokopedia diharapkan tidak hanya memilih selebriti dengan citra bagus dan penampilan menarik. Kepribadian dari selebriti yang dipilih juga perlu diperhatikan agar dapat meningkatkan keyakinan konsumen terhadap selebriti yang di-endorse.

b. Pada variabel online advertising:

1) Tokopedia diharapkan dapat meninjau kembali tampilan iklan yang diiklankan karena tampilan online advertising Tokopedia kurang memberikan reaksi bagi sebagian orang. Tokopedia yang kebanyakan mengiklankan online advertising bersifat hard-selling perlu untuk membuat tampilan iklan yang lebih informatif dan mudah dimengerti oleh semua kalangan tanpa melupakan aspek kreatif, inovatif dan entertain yang akan berdampak untuk dapat meningkatkan penjualannya.

2) Tokopedia diharapkan lebih menyaring iklan-iklan dari seller (penjual) mana saja yang dapat diiklankan. Iklan-iklan yang muncul seringkali bukan dari penjual yang terpercaya dan kredibel. Dan membuat iklan yang ditampilkan menjadi tidak terpercaya dan kredibel. Salah satu cara agar iklan menjadi lebih terpercaya dan kredibel adalah dengan cara menyaring penjual dengan rating tinggi yang bisa mengiklankan produknya.

c. Pada variabel word of mouth, Tokopedia diharapkan mampu meningkatkan performa agar mampu meningkatkan kepuasan konsumen sehingga keingingan konsumen untuk melakukan promosi word of mouth dengan lebih menarik meningkat agar mampu menarik konsumen baru.

\section{REFERENSI}

Andaru, Y. A., dan Pradekso, T. (2016). The Influence of Internet Advertising, Sales Promotion and Peer Group on Interest Buying of Fashion Product in Online Fashion Store. Interaksi Online, Vol. 15.

Aprilia, F. (2015). “Pengaruh Word of Mouth Terhadap Minat Berkunjung Serta Dampaknya Pada Keputusan Berkunjung (Survei pada Pengunjung Tempat Wisata “Jawa Timur Park 2" Kota Batu)". Jurnal Administrasi Bisnis, Vol. 24.

Aqsa, M. (2018). Pengaruh Iklan Online Terhadap Sikap Dan Minat Beli Konsumen Secara Online di Kota Palopo (Survei pada Pengguna Internet di Kota Palopo). Prosiding, 3(1).

Aqsa, M., dan Kartini, D. (2015). “Impact of Online Advertising on Consumer Attitudes and Interests Buy Online (Survey on Students of Internet Users in Makassar)". International Journal of Scientific \& Technology Research, Vol. 4 (4), 230-236.

Arief, G. M., dan Millanyani, Y. (2015). Pengaruh Social Media Marketing Melalui Instagram Terhadap Minat Beli Konsumen Sugar Tribe. EProceedings of Management, Vol. 2 (3). 
Arnianti, Y., dkk (2019). “Pengaruh Ikln Youtube Terhadap Minat Beli Vivo Smartphone (Survei Pada Mahasiswa Universitas Singaperbangsa Karawang Jurusan Manajemen Angkatan 2016, 2017 dan 2018)". Cakrawala Management Business Journal, Vol. 2 (1), 172184.

Astuti, R. L. M. B., dan Santoso, Y. P. (2016). "Pengaruh Promosi Online dan Celebrity Endorser Terhadap Minat Beli Konsumen Tas Online Shop Fani House". Interaksi Online, Vol. 17, 1-10.

Bues, M., dkk (2017). “How Mobile In-Store Advertising Influences Purchase Intention: Value Drivers and Mediating Effects from a Consumer Perspective". Psychology \& Marketing, Vol. 34, 157-174.

Chang, C. C., dan Chin, Y. C. (2010). "The Impact of Recommendation Sources on Online Purchase Intentions: The Moderating Effects of Gender and Perceived Risk". World Academy of Science, Engineering and Technology, Vol. 66, 111-114.

Ferdinand, A. (2014). Metode Penelitian Manajemen, Semarang, Badan Penerbit Universitas Diponegoro.

Islamy, A. Y. N., dan Yoestini, Y. (2019). “Analisis Pengaruh Iklan Online, Kualitas Website dan Kepercayaan Terhadap Keputusan Pembelian Melalui Minat Beli (Studi pada Konsumen Situs Online Travel Agent Tiket. com)". Jurnal Ekonomika Dan Bisnis.

Jurnia, M., dan Rosyad, U. N. (2015). Kajian Hubungan Antara Iklan Di Media Sosial Dengan Minat Beli Konsumen. Jurnal Bisnis Dan Ekonomi, Vol. 2 (4), 12-18.

Kalele, B., Oroh, S. G., \& Sumarauw, J. (2015). “Pengaruh Word of Mouth, Daya Tarik Iklan, Persepsi Harga Dan Kualitas Produk Terhadap Minat Beli Motor Suzuki Satria Fu Pada PT. Sinar Galesong Mandiri". Jurnal EMBA: Jurnal Riset Ekonomi, Manajemen, Bisnis Dan Akuntansi, Vol. 3 (3).

Khan, M. M. (2018). "Effect of Celebrity Endorsement on Consumer Purchase IntentionEvidence From Q-Mobile Linq Advertisement". Pakistan Business Review, Vol. 19, 10651082.

Kotler, P. (2000). Prinsip-prinsip pemasaran manajemen. Jakarta: Prenhalindo.

Kotler, P and Amstrong G. (2012). Principles of Marketing. New Jersey: Pearson Education Limited.

Kotler, P., dan Keller, K. L. (2016). Marketing Management (15th ed.). Pearson Education, Inc. Lim, W. M. (2015). "Influence of Internet Advertising and Electronic Word of Mouth on Consumer Perceptions and Intention: Some Evidence From Online Group Buying". Journal of Computer Information Systems, Vol. 55, 81-89.

Lin, L. Y., dan Lu, C. Y. (2010). “The Influence of Corporate Image, Relationship Marketing and Trust on Purchase Intention: The Moderating Effects of Word of Mouth". Tourism Review.

Mubarok, D. A. A. (2016). "Pengaruh Celebrity Endorsement Terhadap Minat Beli Konsumen". E-Jurnal STIE INABA, Vol. 15, 1-16.

Nurvidiana, R. (2015). “Pengaruh Word of Mouth Terhadap Minat Beli Serta Dampaknya Pada Keputusan Pembelian (Survei Pada Konsumen Republica Cafe Malang Jalan MT. Haryono Gg. XI Malang)". Jurnal Administrasi Bisnis, Vol. 22. 
Prabowo, I. J. K. G. (2016). “Pengaruh Citra Merek, Kualitas Produk, Persepsi Harga dan Word of Mouth Terhadap Minat Beli (Studi pada Mahasiswa Fakultas Ekonomi UNY pengguna Iphone)". Jurnal Manajemen Bisnis Indonesia (JMBI), Vol. 5 (3), 246-256.

Pratiwi, I., dan Moeliono, N. N. K. (2015). "Pengaruh Celebrity Endorser Maudy Ayunda Terhadap Minat Beli Produk Teh Javana (Studi Pada Masyarakat di Kota Bandung)". EProceedings of Management, Vol. 2 (3).

Savitri, N. Y. (2017). “Pengaruh Celebrity Endorser dan Iklan Nelalui Media Televisi Terhadap Minat Beli Pada Tokopedia di Denpasar". E-Jurnal Manajemen, Vol. 6 (8), 4214-4239.

Schiffman dan Kanuk. (2009). Perilaku Konsumen. Edisi Ketujuh. Jakarta.

Shimp, T. A. (2014). Komunikasi Pemasaran Terpadu Dalam Periklanan dan Promosi (8th ed.). Jakarta: Salemba Empat.

Sumarwan, U. (2010). Pemasaran Strategik, Perspektif Value-Based Marketing dan Pengukuran Kinerja. Bogor: IPB Press.

Sweeney, J. C., dkk (2012). "Word of mouth: measuring the power of individual messages". European Journal of Marketing.

Tanjung, S., dan Hudrasyah, H. (2019). “The Impact of Celebrity and Non-Celebrity Endorser Credibility in The Advertisiment on Attitude Towards Advertisiment, Attitude Towards Brand, and Purchase Intention". Jurnal Ekonomi dan Bisnis.

Totoatmojo, K. M. (2015). The Celebrity Endorser (Selebgram) Effect Toward Purchase Intention on Instagram Social Media. Asian Academic Society International Conference Proceeding Series.

Utarsih, Y. (2019). Pengaruh Celebrity Endorser Terhadap Minat Beli Kartu AS (Studi Kasus Pada Penduduk Bandung). Jurnal Ilmu Manajemen, Vol. 1 (2).

Vien, C. V, dkk (2018). “The Effect of Celebrity Endorsement on Brand Attitude and Purchase Intention". Journal of Global Business and Social Entrepreneurship (GBSE), Vol. 1 (4), 141-150.

Widjaja, A. T. (2016). "Pengaruh Word of Mouth dan Electronic Word of Mouth Terhadap Purchase Intention: Sebuah Studi Kasus Mengenai Perilaku Konsumen Terhadap Jasa Ojek Online Gojek". Jurnal Bisnis Dan Manajemen, Vol. 53. 